\title{
Outcomes of orbital malignancies treated with eye-sparing surgery and adjuvant particle radiotherapy: a retrospective study
}

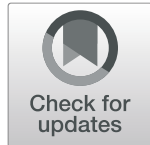

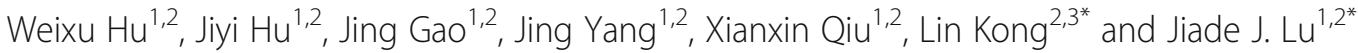

\begin{abstract}
Background: To report the clinical experience of eye sparing surgery (ESS) and adjuvant carbon-ion or proton radiotherapy (CIRT or PRT) for orbital malignancies.

Methods: An analysis of the retrospective data registry from the Shanghai Proton and Heavy lon Center for patients with orbital tumors was conducted. The 2-year local progression-free, regional recurrence-free, distant metastasis-free, progression-free, and overall survival (LPFS, RRFS, DMFS, PFS, OS) rates as well as associated prognostic indicators were analyzed. Radiotherapy-induced acute and late toxicities were summarized.

Results: Between 7/2014 to 5/2018, 22 patients with orbital malignancies of various pathologies received ESS followed by CIRT (18), PRT (1), or PRT + CIRT boost (3). With a median follow-up of 20.25 (range 3.8-38.8) months, the 2-year OS, PFS, LPFS, RRFS, and DMFS rates were 100, 57.9, 92.9, 93.3, and 72.8\%, respectively. No acute severe (i.e., $\geq$ grade 3) toxicity was observed. Two patients experienced severe visual impairment as late toxicities.
\end{abstract}

Conclusion: With few observed acute and late toxicities, particle radiotherapy following ESS provided effective local control with infrequent severe toxicities for patients with orbital malignancies.

Keywords: Particle radiotherapy, Orbital malignancies, Eye-sparing surgery

\section{Background}

Orbital tumors are relatively rare with an incidence of $3.4 / 10^{6}$ person-years [1]; however, its management poses a major challenge to oncologists due to the complexities in the pathologies of the tumors and their proximity to the critical organs at risk (OARs).

Orbital malignancies can arise from any of the orbital structures such as extra-ocular muscles, fat, glands, vessels, nerves, and ocular adnexa. Extensive resection inevitably causes vision damage and disfigurement. Eye-sparing surgery (ESS) is the current preferred primary treatment for nearly all types of neoplasm of epithelial or mesenchymal origin [2]; nevertheless, sufficient margins are difficult to achieve especially for locally advanced diseases. Limited resection poses a high risk of local recurrence.

\footnotetext{
* Correspondence: lin.kong@sphic.org.cn; jiade.lu@sphic.org.cn

${ }^{2}$ Shanghai Engineering Research Center of Proton and Heavy lon Radiation

Therapy, 4365 Kangxin Road, Pudong, Shanghai 201321, China

${ }^{1}$ Department of Radiation Oncology, Shanghai Proton and Heavy lon Center,

Shanghai, China

Full list of author information is available at the end of the article
}

Multidisciplinary approach including surgery followed by adjuvant radiotherapy or chemoradiation is usually needed for orbital malignancies. Intensity-modulated radiotherapy (IMRT) has been used adjuvantly after surgery or in definitive settings for unresectable cases; however, radiation-induced toxicity limits the doses of IMRT to tumor targets due to excessive entrance and exit doses in the beam paths [3]. Lower doses are usually insufficient for controlling the more commonly diagnosed orbital malignancies including squamous cell carcinoma, adenoid cystic carcinoma (ACC) and soft-tissue sarcoma (STS) [1, 2, 4-6].

There is an increasing interest in the use of particle radiotherapy such as carbon-ion or proton radiotherapy (CIRT or PRT) in the management of head and neck malignancies, particularly for those occurred close to critical OARs, such as orbital tumors [7]. Due to its unique physical characteristic of Bragg Peak, particle radiotherapy allows for providing a high-dose coverage to the tumor with relatively low entrance and minimal exit doses $[8,9]$. The use of 
intensity-modulated particle therapy (IMPT) technology may further improve dose distribution and reduce adverseeffects without compromising efficacy in the treatment of cancers within complex anatomical scenario thereby improves the therapeutic ratio $[10,11]$.

Carbon-ion beam has higher linear energy transfer (LET) and relative biological effectiveness (RBE) as compared to those of photon or proton [12-15]. The advantages in both physical and biological characteristics of carbon ion, in theory, make it more suitable in the management of conditions with both anatomic limitations and the radio-resistance such as ACC, melanoma, and sarcoma of the orbit. However, data describing clinical outcomes after particle radiotherapy especially CIRT for tumors of the orbit or ocular adnexa is lacking.

The Shanghai Proton and Heavy Ion Center (SPHIC) started to provide IMPT using pencil beam scanning (PBS) technology in 5/2015 [16]. In this article, we report the outcomes in terms of efficacy and safety of a group of patients with orbital tumors treated with adjuvant particle radiotherapy after ESS.

\section{Methods}

\section{Pretreatment evaluation}

Pretreatment evaluations included a complete history and physical examination (H\&P), complete blood count (CBC), serum electrolytes, and MRI or CT (if MRI was contraindicated) of the head and neck region. PET-CT was performed if clinically indicated.

All patients were staged with the AJCC staging system (7th or 8th edition depend on the date of diagnosis). All protocols were registered to the institutional review board (IRB) of the SPHIC. All cases were discussed in the multidisciplinary tumor clinic of SPHIC to confirm the indication of adjuvant particle radiotherapy before inclusion into the institutional cancer registry and planning.

\section{IMPT and chemotherapy}

All patients were immobilized with AlphaCradle ${ }^{\circ}$ and thermoplastic masks in supine position. Plain CT for simulation from the vertex to the inferior margin of clavicular heads were performed at $1.5-\mathrm{mm}$ slice thickness. MRI-CT fusion was performed for all patients prior to target delineation. The gross tumor volume (GTV) was defined as the tumor discovered on clinical examination or imaging studies for patients with incomplete surgical resection. We define clinical target volume (CTV) covering post-surgical GTV (CTV-G) after R2 resection/biopsy to deliver prescribed doses as GTV plus 1-3 mm margin (depend on the proximity to OARs). CTV for patients with R1 resection or achieved complete response (CR) after chemotherapy included pretreatment tumor bed plus high-risk areas for tumor extension. An additional 3-6 mm margin was added to the CTVs to create the planning target volume (PTV) for uncertainty with regard to dose distribution and potential setup errors.

Doses of particle radiotherapy were measured by Gyequivalents (GyE) to account for the RBE differences compared to photon. Dose constraints of critical OARs are based on TD5/5 described by Emami et al. [17] except for optic nerve (D20 < 30GyE) and temporal lobes (V40 $<7.66 \mathrm{cc}$; V50 $<4.66 \mathrm{cc}$ ) set forth by the National Institute or Radiation Science of Japan [18]. For patients who had previous photon-based radiation, old treatment plans were obtained. Recovery from previous radiotherapy doses was set at 70\% [19]. Planning for particle radiotherapy were performed using the Siemens Syngo ${ }^{\circ}$ treatment planning system.

CIRT and PRT were delivered with PBS technology. Two-3 beams were typically delivered from the horizontal or $45^{\circ}$ directions. Setup accuracy was confirmed using bony landmarks on orthogonal X-ray on daily basis. Weekly CT were required to verify tumor regression/progression and anatomic changes. Chemotherapy was used at the discretion of the attending oncologists.

\section{Follow-up}

All patients were admitted and examined daily during particle radiotherapy. After the discharge, all patients were encouraged to be followed-up using the standardized institutional follow-up protocol. The first follow-up was provided within 4-6 weeks after the completion of treatment. Patients were then followed-up every 3 months in the first 2 years, every 6 months in the following 3 years, and annually thereafter. A complete H\&P with a focus to the eyes, orbits, head/neck region, as well as MRI of the head area are required at each follow-up. Other studies are ordered if clinically indicated.

\section{Data analysis}

The duration of survival was calculated from the diagnosis of the disease until death or the last follow-up. The time to locoregional or distant failure was measured from the initiation of any treatment until disease progression or recurrence. Freedom from failure and OS rates were calculated using the Kaplan-Meier method. Cox regression model as was used for both uni- and multi-variate analyses to compare the difference of the survival probabilities and to define significant prognostic factors. All analyses were performed using the SPSS statistics package (Version 22.0).

Adverse events were scored by the attending radiation oncologist(s) according to the CTCAE (version 4.03). Acute toxicities included the adverse events occurred during or within 3 months after the initiation of particle radiotherapy. Late toxicity was defined as those occurred after 3 months from or persisted for $>3$ months after the initiation of particle radiotherapy. 


\section{Results}

\section{Characteristics of patients and surgery}

Between 11/2015 and 6/2018, 23 consecutive patients with orbital tumor were treated at SPHIC. All patients had ESS before particle radiotherapy. One patient was excluded from this analysis due to a change of diagnosis from pathology confirmation in the mid of CIRT which substantially changed treatment. The median follow-up of the remaining 22 patients was 20.25 (range 3.8-38.8) months.

Most patients $(81.8 \%)$ presented with malignancies of the lacrimal gland or lacrimal sac, and $77.2 \%$ had malignancies of epithelial origin. One patient presented with locally recurrent lacrimal gland ACC had ESS twice. She also received photon-based radiotherapy (60Gy/30Fx) after the first surgery. The characteristics of the patients, their diseases, and treatment were detailed in Table 1.

\section{Particle radiotherapy}

PRT, CIRT, or their combination were used in 1, 18, and 3 patients with curative intention, respectively. The median time between surgery and particle therapy was 2.2 months (range 1.2-6.13).

Three patients who achieved R0 resection received PRT (56 GyE/28 fractions, 1 case) or CIRT (60 GyE/20 fractions, 2 cases), respectively. For the remaining 19 patients, 3 received PRT (56 GyE/28 fractions) followed by CIRT boost (15 GyE/3 fractions), and 16 received CIRT (60-70 GyE for primary/residual tumor and 54-62GyE for CTVs in 18-23 fractions using simultaneous integrated boost technique). Elective nodal irradiation was not performed for any patients. All 22 patients completed particle radiotherapy without break. A typical treatment plan is illustrated in Fig. 1.

\section{Survival outcomes}

With a median follow-up of 20.25 (range 3.8-38.8) months, all 22 patients were alive. One patient who had R2 resection followed-by cisplatin chemotherapy for T3NOM0 rhabdomyosarcoma of the lacrimal sac developed local recurrence at 17.8 months after CIRT. Another with R2 resected T4N0M0 ACC of the lacrimal gland developed regional recurrence after PRT + CIRT boost at 11.5 months. The 2-year local-progression-free and regional-recurrence-free survival (LPFS and RRFS) rates were 92.9 and 93.3\%, respectively (Fig. 2a \& b). Four patients with lacrimal gland malignancies ( 2 with ACC and 2 with adenocarcinoma, 2 with T2 and 2 with T4 disease) developed distant metastasis (DM) at a median time of 9.47 months (range 8.13-20.8). The 2-year DM-free survival (DMFS) rate was $72.8 \%$, and the 2-year progression free survival (PFS) rate was $57.9 \%$ (Fig. 2c \& d) for the entire cohort. None of the 13 patients with lacrimal gland malignancy developed local failure or progression (i.e., LPFS $=100 \%$ ). The 2-year RRFS, DMFS and PFS were 88.9 and $53.0 \%$ and $39.3 \%$ for patients with lacrimal gland malignancies, respectively.
Table 1 Characteristics of patients, their disease, and treatment

\begin{tabular}{|c|c|}
\hline Characteristic & No. of patients (\%) \\
\hline Median age (range) & $46.5(14-74)$ \\
\hline \multicolumn{2}{|l|}{ Sex } \\
\hline Male & $14(63.6)$ \\
\hline Female & $8(36.4)$ \\
\hline \multicolumn{2}{|l|}{ Tumor site } \\
\hline Lacrimal gland & $13(59.1)$ \\
\hline Lacrimal sac & $5(22.7)$ \\
\hline Orbital bone & $1(4.5)$ \\
\hline Other & $3(13.6)$ \\
\hline \multicolumn{2}{|l|}{ Tumor histology } \\
\hline Adenoid cystic carcinoma & $11(50.0)$ \\
\hline Adenocarcinoma & $5(22.7)$ \\
\hline Squamous cells carcinoma & $1(4.5)$ \\
\hline Melanoma & $1(4.5)$ \\
\hline rhabdomyosarcoma & $1(4.5)$ \\
\hline desmoplastic small round cell tumor & $1(4.5)$ \\
\hline alveolar soft part sarcoma & $1(4.5)$ \\
\hline chondrosarcoma & $1(4.5)$ \\
\hline \multicolumn{2}{|l|}{ T category } \\
\hline $\mathrm{T} 1$ & $2(9.1)$ \\
\hline $\mathrm{T} 2$ & $7(31.8)$ \\
\hline T3 & $4(18.2)$ \\
\hline T4 & $9(40.9)$ \\
\hline \multicolumn{2}{|l|}{ Tumor status } \\
\hline Primary & $21(95.5)$ \\
\hline Recurrence & $1(4.5)$ \\
\hline \multicolumn{2}{|l|}{ Surgical margin } \\
\hline RO & $3(13.6)$ \\
\hline R1 & $6(27.3)$ \\
\hline R2 or biopsy & $13(59.1)$ \\
\hline \multicolumn{2}{|l|}{ Interval from surgery to radiotherapy, mo } \\
\hline Median (range) & $2.2(1.2-6.13)$ \\
\hline \multicolumn{2}{|l|}{ Radiotherapy technique } \\
\hline PRT & $1(4.5)$ \\
\hline CIRT & $18(81.8)$ \\
\hline $\mathrm{PRT}+\mathrm{CIRT}$ & $3(13.6)$ \\
\hline \multicolumn{2}{|l|}{ Radiotherapy dose (Gy BED) } \\
\hline Median (range) & $85.05(67.2-94.5)$ \\
\hline \multicolumn{2}{|l|}{ GTV $(\mathrm{ml})$} \\
\hline Median (range) & $16.0(1.9-67.6)$ \\
\hline \multicolumn{2}{|l|}{ CTV (ml) } \\
\hline Median (range) & $43.4(18.8-209.9)$ \\
\hline \multicolumn{2}{|c|}{ Concurrent chemotherapy or immunotherapy } \\
\hline Cisplatin & $2(9.1)$ \\
\hline Interferon $a-2 b$ & $1(4.5)$ \\
\hline No & $19(86.4)$ \\
\hline
\end{tabular}



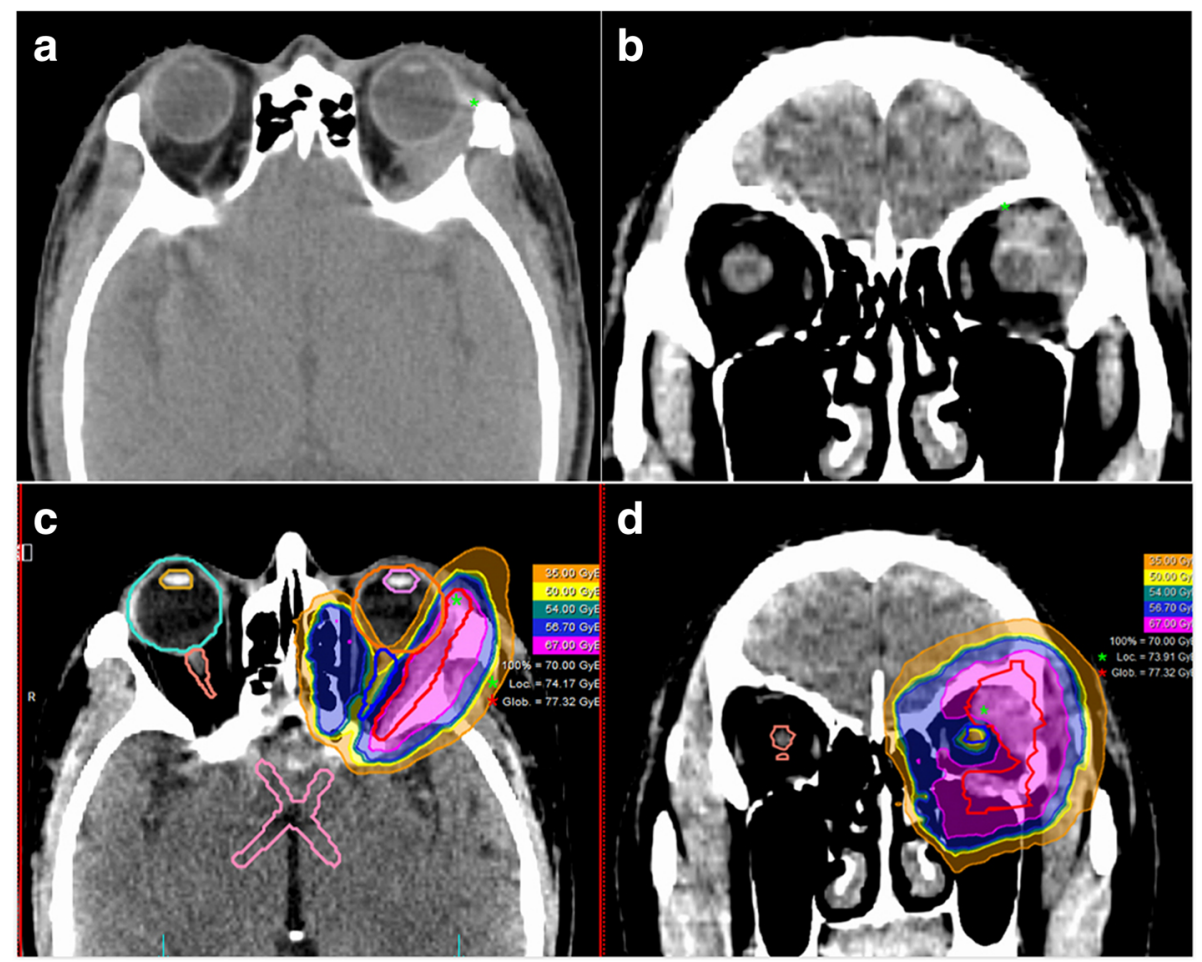

Fig. 1 Axial (a) and coronal (b) views of a post eye sparing surgery CT scan of a patient with left lacrimal gland ACC. Axial (c) and coronal (d) views of a typical intensity-modulated carbon ion radiotherapy treatment plan

\section{Acute and chronic toxicities}

The characteristics of acute and late toxicities are summarized in Table 2 . Nine patients $(40.9 \%)$ experienced grade 1 or 2 acute toxicities induced by particle radiotherapy. No acute toxicity of grade 3 or above was observed. Seven patients $(31.8 \%)$ experienced late toxicities of various grades including 3 with grade 1 dry eyes, 1 with grade 1 brain injury, 1 with grade 2 retinopathy, 1 with grade 3 visual impairment and 1 with blindness in the affected eye (grade 4). During the follow-up period, no vision impairment was observed, except for 2 patients developed grade 3 and grade 4 visual acuity reduction after CIRT. One of them experienced ipsilateral vision acuity reduction from normal to 20/ 200-40/200 at 6 months accompanied by optic atrophy diagnosed by MRI; the other patient developed blindness at 3 months without changes on MR scan. One patient who has affected eyeball fixation due to twice eye-sparing surgery and photon-based radiotherapy prior to re-irradiation by CIRT, and no ocular movement disorder was observed in remaining patients who received particle radiotherapy. In addition, there was no eye injury in contralateral side in all patients at present.

\section{Prognostic factors}

Univariate analyses using log-rank test indicated tumors with mesenchymal origins had a trend toward a worse LPFS ( $p=0.056)$ (Table 3, Fig. 3a). In addition, tumors of lacrimal gland had a trend with worse DMFS $(p=0.072)$ (Table 3, Fig. 3b). When BED was taken as a continuous variable using Cox regression analysis, higher BED had a trend to associate with improved DMFS (hazard ratio, 0.884; 95\% CI, 0.776-1.007 [P=0.064]) (Table 4). However, margin status, T-classification, volume of GTV or CTV did not associate with PFS, LPFS, RRFS or DMFS in both logrank test and Cox regression analysis (Tables 3 \& 4).

Multivariate analysis using Cox regression using tumor correlation factors such as histological type, BED (continuous variable), T-classification, volume of GTV and CTV suggested a significant relationship for higher BED with improved PFS (hazard ratio, 0.732; 95\% CI, 0.557$0.960[P=0.024])$ and a trend with improved DMFS (hazard ratio, 0.717; 95\% CI, 0.512-1.004 [P=0.053]). Furthermore, larger CTV field may improve PFS (hazard ratio, 0.952; 95\% CI, 0.906-1.001 [P=0.054]) (Table 5).

\section{Discussion}

We analyzed 22 patients with orbital tumor after ESS followed by PRT and/or CIRT. With a median follow-up of 20.3 months, the 2-year OS, PFS, LPFS, RRFS, and DMFS rates were $100,57.9,92.9,93.3$, and $72.8 \%$, respectively. No acute severe (i.e., $\geq$ grade 3 ) toxicity was observed. The occurrences of severe late toxicities were also infrequent. These findings suggest that particle radiotherapy after ESS 


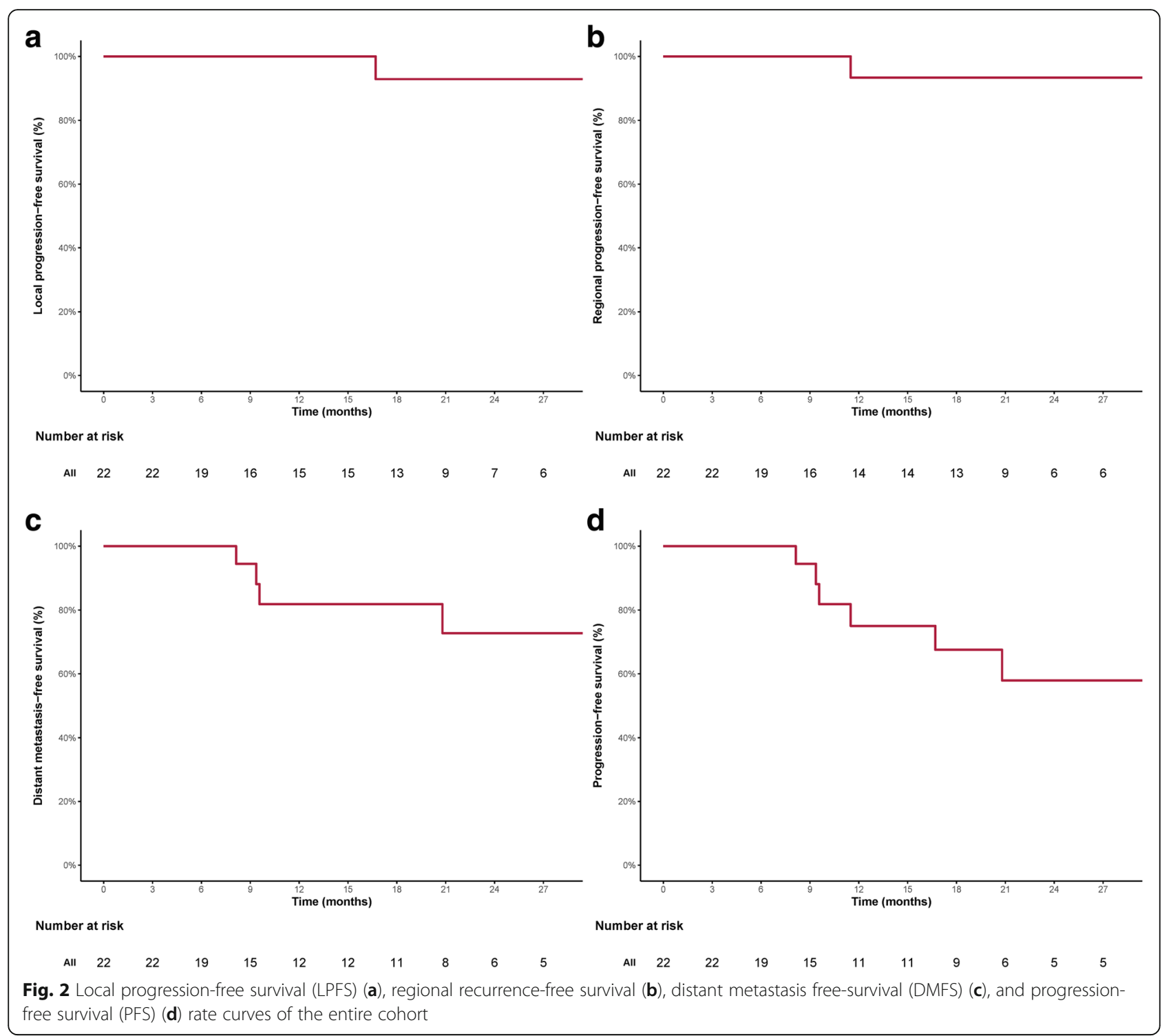

could provide satisfactory local control with acceptable toxicities at 2 years for patients with orbit tumors. However, DM remains a challenge for overall disease control.

Due to the complexity of the anatomy, ocular exenteration was advocated histologically; however, disease control remained suboptimal. In a report of 39 patients with orbital malignancies received exenteration with (10 patients) or without (29 patients) adjuvant radiation, $\sim 20 \%$ experienced local recurrence after a median follow-up of 34.7 weeks. The 3-year OS and recurrence/death-free survival rates were 50.5 and $47.5 \%$, respectively [20]. Results from multiple retrospective studies revealed that 5-year LPFS ranged at $20-22 \%$ after surgery (exenteration or eye spearing) without adjuvant radiation [21, 22]. Adjuvant radiotherapy following exenteration produced substantially improved local control as compared to surgery alone. Three- or 5-year LPFS rates of $60 \sim 65 \%[21,23]$, with similar OS rates of $60 \%$ have been reported. In a more recently published series, adjuvant IMRT after exenteration produced a 3-year LPFS and OS rates of 91 and $70 \%$, respectively [24].

ESS provides an important opportunity for function preservation for patients with orbital tumors. Disease control and survival rates after less aggressive (i.e., eye-sparing) surgery assimilates those from exenteration when adjuvant radiotherapy was added. In 11 lacrimal gland tumor patients treated with ESS, only 1 patient declined adjuvant radiotherapy and developed local recurrence [25]. A more recently published series of 37 patients with lacrimal gland carcinoma ( $>80 \%$ with $\mathrm{T} 1$ or T2 diseases) reported a 2 -year recurrence free survival of approximately $95 \%$. Of the 31 patients received adjuvant radiotherapy, 12 had PRT [22]. Although the composition of patients and pathologies in our series differ substantially from the above-mentioned 


\begin{tabular}{|c|c|c|c|c|c|c|c|c|c|c|c|c|}
\hline \multirow[b]{3}{*}{ Type of adverse reaction } & \multicolumn{4}{|c|}{ Acute Toxicities } & \multicolumn{8}{|c|}{ Late Toxicities } \\
\hline & \multicolumn{2}{|c|}{ Grade 1} & \multicolumn{2}{|c|}{ Grade 2} & \multicolumn{2}{|c|}{ Grade 1} & \multicolumn{2}{|c|}{ Grade 2} & \multicolumn{2}{|c|}{ Grade 3} & \multicolumn{2}{|c|}{ Grade 4} \\
\hline & No. & $\%$ & No. & $\%$ & No. & $\%$ & No. & $\%$ & No. & $\%$ & No. & $\%$ \\
\hline Epiphora & 1 & 4.5 & & b & & 0 & & 0 & & 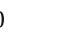 & & b \\
\hline Conjunctival congestion & & & 1 & 4.5 & & 0 & & 0 & & 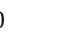 & & 0 \\
\hline Periorbital edema & 7 & 31.8 & & 0 & & 0 & & 0 & & 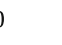 & & b \\
\hline Decreased vision & & & & 0 & & 0 & & 0 & 1 & 4.5 & 1 & 4.5 \\
\hline Dry eyes & & & & o & 3 & 13.6 & & 0 & & 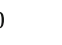 & & b \\
\hline Retinopathy & & & & b & & 0 & 1 & 4.5 & & 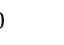 & & b \\
\hline Brain injury & & & & o & 1 & 4.5 & & 0 & & 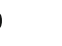 & & 0 \\
\hline Total & 8 & 36.4 & 1 & 4.5 & 4 & 18.2 & 1 & 4.5 & 1 & 4.5 & 1 & 4.5 \\
\hline
\end{tabular}

papers, the outcomes remain encouraging. All 22 patients were alive at the time of analysis with a 2-year LPFS rate of $92.9 \%$, although $\sim 60 \%$ of patients in our series presented with T3/T4 diseases. Furthermore, patients with lacrimal gland tumors achieved 2-year LPFS and RRFS rates of 100 and $88.9 \%$, respectively, although $\sim 40 \%$ had T4 disease. Our results mimicked the most favorable 2-year outcome in terms of survival and local control despite of a less favorable clinical presentation [21, 24, 26, 27].

With effective locoregional control, DM became the most common mode of failure in patients with orbital malignancies. DM rate of $27.5 \%$ and 3-year DMFS of $70 \%$ were reported for orbital carcinomas [23]. However, $\mathrm{DM}$ is more challenging for lacrimal glade cancer especially adenoid cystic carcinoma [21, 23]. Skinner et al. [21] reported a 5-year DMFS rate of $65 \%$ for lacrimal gland carcinoma patients, and found that DM was not correlated with histopathology, surgical margin or type of surgery (eye-spearing vs. exenteration). These results were in line with our finds, of which DM was seen in $30.8 \%$ of lacrimal gland patients. Furthermore, the 2-year DMFS of our entire cohort and those with lacrimal gland malignancies were 71.6 and 53\%, respectively. Our univariate analysis indicated a trend for DM in patients with lacrimal gland malignancies $(P=0.072)$. In both the univariate and multivariate analysis, factors such as histopathology, surgical margin status, or T-classification were not associated with DMFS. However, BED may have significant impact on DMFS: The higher the BED, the lower the risk of DM. Moreover, the overall PFS, largely related to DMFS, is not only significantly associated with BED but also may correlated with CTV volume $(P=0.053)$. These findings suggested that particle therapy may have a significant impact on disease control due to its improved conformality secondary to its physical characteristics. Well localized and more precise dose

Table 3 Univariate analysis by the log-rank test

\begin{tabular}{|c|c|c|c|c|}
\hline Characteristics & PFS & LPFS & RRFS & DMFS \\
\hline Gender & 0.910 & 0.527 & 0.480 & 0.362 \\
\hline Age $(<46.5$ y vs. $>46.5$ y) & 0.442 & 0.527 & 0.480 & 0.847 \\
\hline Tumor site (other vs. lacrimal gland) & 0.118 & 0.248 & 0.414 & 0.072 \\
\hline Origin (mesenchymal vs. epithelial histology) & 0.653 & 0.056 & 0.617 & 0.254 \\
\hline T classification (T1/2 vs. T3/4) & 0.524 & 0.386 & 0.414 & 0.784 \\
\hline Surgical margin (R0 + R1 vs. R2) & 0.887 & 0.317 & 0.350 & 0.221 \\
\hline BED (<85.05 GyE vs. $\geq 85.05$ GyE) & 0.813 & 0.602 & 0.617 & 0.806 \\
\hline GTV $(<16 \mathrm{ml}$ vs. $>16 \mathrm{ml})$ & 0.928 & 0.527 & 0.157 & 0.666 \\
\hline CTV $(<43.4 \mathrm{ml}$ vs. $>43.4 \mathrm{ml})$ & 0.431 & 0.317 & 0.285 & 0.327 \\
\hline
\end{tabular}




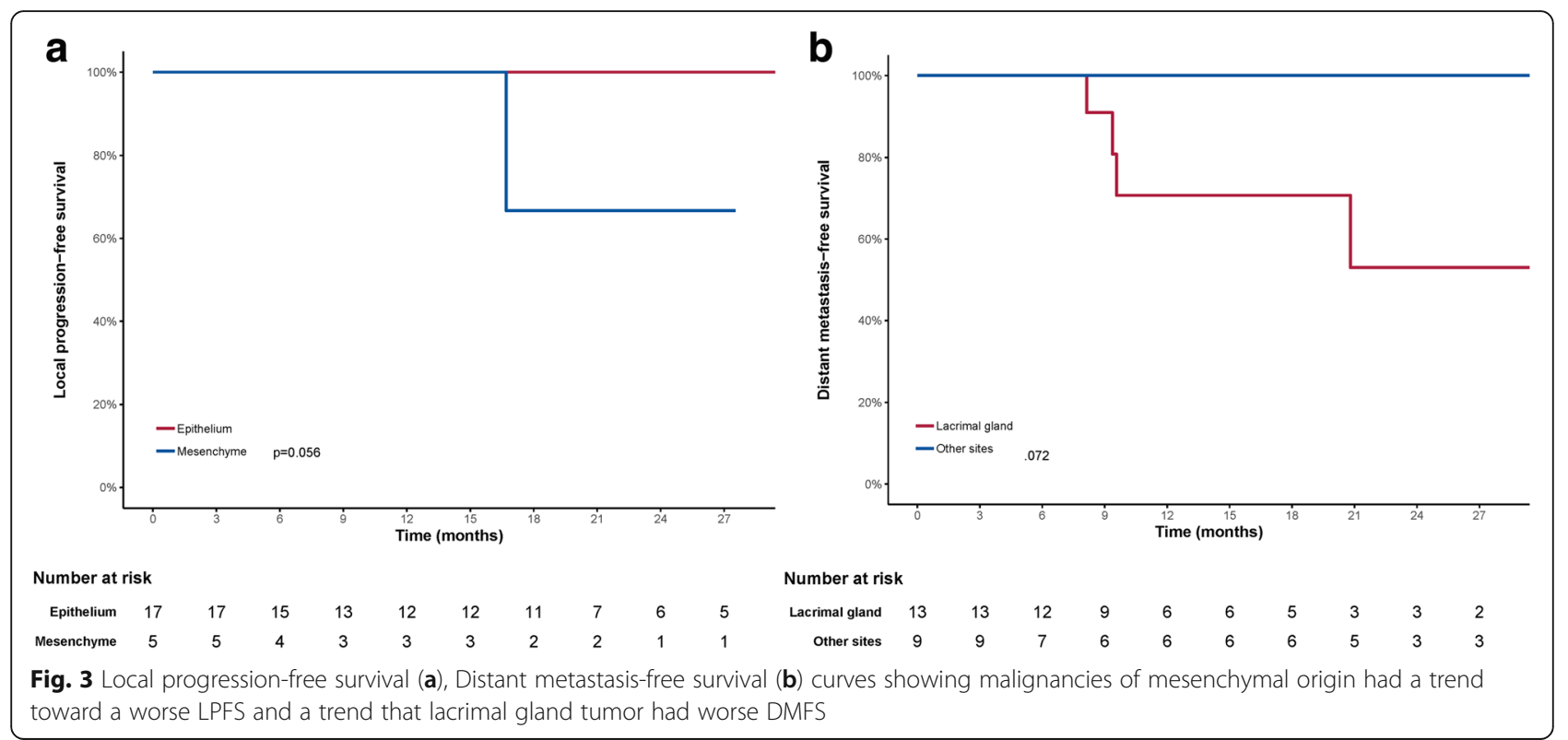

distribution enables higher dose as well as bigger CTV with OAR sparing, a feature that is important in particle radiotherapy for most head and neck cancers [10, 11]. Furthermore, CIRT not only provide advantages in dose distribution, but also biologically due to its higher linear energy transfer (LET). The value of the RBE of carbonion is $2-5: 1$ as compared with photons and protons, which is highly relevant for radio-resistant tumors such as STS $[14,15]$. Our data suggested mesenchymal malignancies of the orbit may pose a higher risk of local recurrence $(p=0.056)$. And our previous experience with
CIRT for head and neck sarcomas revealed favorable disease control with acceptable toxicity profile [28].

In spite of the improved function preservation and locoregional disease control with ESS and adjuvant IMRT, radiation-induced toxicities remained a challenge in the management of orbital tumors due to its anatomical complexity $[29,30]$. Published data indicated that with doses exceeding 50Gy, conjunctival keratinization, lacrimal gland atrophy and fibrosis, corneal decompensation would occur. When doses exceeded 60Gy, symblepharon, keratoconjunctivitis, permanent dry eyes became a concern.

Table 4 Univariate analysis of DMFS and PFS by Cox regression

\begin{tabular}{|c|c|c|c|c|}
\hline \multirow[b]{2}{*}{ Variables } & \multicolumn{2}{|l|}{ DMFS } & \multicolumn{2}{|l|}{ PFS } \\
\hline & $\mathrm{P}$ & HR $(95 \% \mathrm{Cl})$ & $\mathrm{P}$ & HR $(95 \% \mathrm{Cl})$ \\
\hline \multicolumn{5}{|l|}{ Gender } \\
\hline Male & Ref & Ref & Ref & Ref \\
\hline Female & 0.378 & $2.431(0.338-17.48)$ & 0.910 & $1.103(0.202-6.036)$ \\
\hline Age, y & 0.186 & $1.046(0.979-1.118)$ & 0.752 & $1.001(0.958-1.061)$ \\
\hline \multicolumn{5}{|l|}{ Histology } \\
\hline Epithelium & Ref & Ref & Ref & Ref \\
\hline Mesenchyme & 0.488 & $0.031(0.001-560.47)$ & 0.656 & $0.613(0.071-5.280)$ \\
\hline \multicolumn{5}{|l|}{ T classification } \\
\hline $\mathrm{T} 1+\mathrm{T} 2$ & Ref & Ref & Ref & Ref \\
\hline $\mathrm{T} 3+\mathrm{T} 4$ & 0.784 & $0.760(0.107-5.415)$ & 0.529 & $1.731(0.313-9.564)$ \\
\hline \multicolumn{5}{|l|}{ Surgical margin } \\
\hline $\mathrm{R} 0+\mathrm{R} 1$ & Ref & Ref & Ref & Ref \\
\hline R2 & 0.254 & $0.268(0.028-2.579)$ & 0.887 & $0.890(0.178-4.450)$ \\
\hline BED & 0.064 & $0.884(0.776-1.007)$ & 0.100 & $0.898(0.791-1.021)$ \\
\hline $\mathrm{GTV}, \mathrm{ml}$ & 0.948 & $1.002(0.948-1.059)$ & 0.928 & $0.998(0.953-1.045)$ \\
\hline CTV, ml & 0.978 & $1.000(0.980-1.021)$ & 0.797 & $0.998(0.980-1.016)$ \\
\hline
\end{tabular}


Table 5 Multivariate analysis of DMFS and PFS by Cox regression

\begin{tabular}{|c|c|c|c|c|}
\hline \multirow[b]{2}{*}{ Variables } & \multicolumn{2}{|l|}{$\underline{\text { DMFS }}$} & \multicolumn{2}{|l|}{ PFS } \\
\hline & $P$ & $\mathrm{HR}(95 \% \mathrm{Cl})$ & $P$ & $\mathrm{HR}(95 \% \mathrm{Cl})$ \\
\hline \multicolumn{5}{|l|}{ T classification } \\
\hline $\mathrm{T} 1+\mathrm{T} 2$ & Ref & Ref & Ref & Ref \\
\hline $\mathrm{T} 3+\mathrm{T} 4$ & 0.368 & $6.673(0.107-415.609)$ & 0.189 & $6.28(0.406-97.134)$ \\
\hline \multicolumn{5}{|l|}{ Surgical margin } \\
\hline $\mathrm{R} 0+\mathrm{R} 1$ & Ref & Ref & Ref & Ref \\
\hline R2 & 0.233 & $0.042(0-7.646)$ & 0.969 & $1.059(0.059-18.20)$ \\
\hline \multicolumn{5}{|l|}{ Histology } \\
\hline Epithelium & Ref & Ref & Ref & Ref \\
\hline Mesenchyme & 0.976 & 0 & 0.384 & $0.255(0.012-5.548)$ \\
\hline BED & 0.053 & $0.717(0.512-1.004)$ & 0.023 & $0.726(0.551-0.957)$ \\
\hline GTV, ml & 0.079 & 1.199 (0.979-1.469) & 0.104 & $1.117(0.977-1.001)$ \\
\hline CTV, ml & 0.095 & $0.946(0.887-1.010)$ & 0.053 & $0.953(0.907-1.278)$ \\
\hline
\end{tabular}

Moreover, the probability of radiation-induced optic neuropathy may occur in $7-20 \%$ of patients $[6,17,31,32]$. Particle radiotherapy provides distinctive advantages for tumors close to critical OARs such as orbital malignancies due to its distinctive physical characteristics. Patterns of treatment-induced adverse effects were studied extensively in a series of 20 orbital tumor patients treated with ESS followed by PRT at M.D. Anderson Cancer Center [7]. Although disease control was not the focus of the study, the authors reported one patient with local and another with regional recurrence. In addition to the $35 \%$ patients who experienced grade 3 acute dermatitis, 30\% experienced grade 3 chronic toxicities of epiphora and eyelid function disorder. In addition, grade 2, 3, and 4 visual decrease were observed in 2, 2, and 1 patient, respectively. The risk of severe chronic toxicity was higher when the maximum corneal dose exceeded 36Gy (BED) [7]. Higher BED was found to associate with improved outcome in our series, indicating the advantage of particle radiotherapy for this condition which usually occur close to dose limiting OARs. CIRT with less penumbra as compared to proton may provide additional physical advantage. In addition, favorable outcomes in terms of radiation-induced toxicities were observed in our series: Only grade 1/2 acute adverse-effects were observed in 9 patients (40.9\%). Approximately $22.7 \%$ of patients developed grade 1 or 2 late effects. Nevertheless, 2 patients experienced severe decrease of vision at 3 and 6 months after CIRT. In both cases the tumors were attached or close to the optic nerve or eye.

Several pitfalls of our study need to be discussed. First, because of variations in certain institutional clinical trial regimens, few patients were treated with PRT (1 cases) or PRT + CIRT boost ( 3 cases) although most patients received CIRT alone. Our analysis largely reflected the results after CIRT for orbital malignancies. Second, orbital tumor includes a group of heterogenous conditions from various origins with substantial different biological behaviors. Combining different pathologies would inevitably affect the uniformity of the results. Third, owing to the limited follow up time, these clinical results must be considered with caution, we will continue to follow up these patients and report clinical outcomes with longer period. Fourth, our study suffered from the nature of retrospective studies with a relatively small sample size; nevertheless, we provided the outcomes of the largest series of orbital tumors treated with particle radiotherapy in terms of disease, control, survival, and safety. Considering the rarity of the condition, nearly all published literatures were retrospective in nature from single institutions. Clearly, prospective investigations to compare efficacies from different treatment modalities or technologies are difficult to initiate without international collaboration among specialized academic centers.

\section{Conclusion}

Adjuvant particle radiotherapy following ESS provided a satisfactory OS and locoregional control at 2 years. DM remained a major form of treatment failure. No severe acute treatment-induced toxicity was observed, and severe late toxicities was observed in $<10 \%$ of cases. Longterm follow-up is needed to confirm the efficacy and safety of adjuvant particle radiotherapy, in particular CIRT, for orbital tumor after ESS.

\section{Abbreviations}

ACC: Adenoid cystic carcinoma; BED: Biological equivalent dose; CBC: Complete blood count; CIRT: Carbon-ion radiotherapy; CR: Complete response; CT: Computed tomography; CTCAE: Common terminology criteria for adverse events; CTV: Clinical target volume; CTV-G: Post-surgical GTV; DMFS: Distant metastasis free survival; ESS: Eye sparing surgery; GTV: Gross tumor volume; GyE: Gy-equivalents; H\&P: History and physical examination; 
IMPT: Intensity-modulated particle therapy; IMRT: Intensity-modulated radiotherapy; IRB: Institutional review board; LET: Linear energy transfer; LPFS: Local progression-free survival; MRI: Magnetic resonance imaging; OARs: Organs at risk; OS: Overall survival; PBS: Pencil beam scanning; PET$\mathrm{CT}$ : Positron emission tomography/computed tomography; PFS: Progression free survival; PRT: Proton radiotherapy; PTV: Planning target volume; RBE: Relative biological effectiveness; RRFS: Regional recurrence-free survival; SPHIC: Shanghai Proton and Heavy lon Center; STS: Soft-tissue sarcoma

\section{Acknowledgements}

Not applicable.

\section{Authors' contributions}

WH: Design of the study, data acquisition, statistical analysis, results interpretation, drafting and revising the article, final approval of the version, responsible for all aspects of the work. $\mathrm{JH}$ : data acquisition, data analysis, drafting and revising the article, version approval, responsible for all aspects of the work. JG: data acquisition, drafting and revising the article. JY: data acquisition, revising the article, final approval of the version, responsible for all of the work. XQ: data acquisition, revising the article, version approval, responsible for all aspects of the work. LK: Conceptualization and design of the of study, data analysis and interpretation, drafting and revising the article, funding acquisition, final approval of the version, responsible for all aspects of the work. Jال J: Conceptualization and design of the study, data analysis, interpretation of the results, drafting and revising the article. All authors approved the submitted version, agreement to be accountable for all aspects of the work.

\section{Funding}

This work was supported by Shanghai Municipal Commission of Health and Family Planning (Project No. 20164Y0155), Pudong New Area Science and Technology Development Foundation (Project No. PKJ2016-Y41). The funders had no role in design of the study, in the data collection, analysis, or interpretation of data, in the decision to publish, or in the writing of the manuscript.

\section{Availability of data and materials}

The datasets used and/or analyzed during the current study are available from the corresponding author on reasonable request.

\section{Ethics approval and consent to participate}

This retrospective study was approved by the Ethics Committee of Shanghai Proton and Heavy lon Center. Written informed consent was obtained for each participant before enrolling in this study.

\section{Consent for publication}

Written informed consent for publication was obtained for each patient before enrolling in this study.

\section{Competing interests}

The authors declare that they have no competing interests.

\section{Author details}

'Department of Radiation Oncology, Shanghai Proton and Heavy lon Center, Shanghai, China. ${ }^{2}$ Shanghai Engineering Research Center of Proton and Heavy lon Radiation Therapy, 4365 Kangxin Road, Pudong, Shanghai 201321, China. ${ }^{3}$ Department of Radiation Oncology, Shanghai Proton and Heavy lon Center, Fudan University Shanghai Cancer Center, Shanghai, China.

Received: 18 February 2019 Accepted: 22 July 2019

Published online: 06 August 2019

\section{References}

1. Hassan WM, Bakry MS, Hassan HM, Alfaar AS. Incidence of orbital, conjunctival and lacrimal gland malignant tumors in USA from surveillance, epidemiology and end results, 1973-2009. Int J Ophthalmol. 2016;9(12):1808-13.

2. Mallen-St Clair J, Arshi A, Tajudeen B, Abemayor E, St John M. Epidemiology and treatment of lacrimal gland tumors: a population-based cohort analysis. JAMA Otolaryngol Head Neck Surg. 2014;140(12):1110-6.

3. Rosenthal DI, Chambers MS, Fuller CD, Rebueno NC, Garcia J, Kies MS, Morrison WH, Ang KK, Garden AS. Beam path toxicities to non-target structures during intensity-modulated radiation therapy for head and neck cancer. Int J Radiat Oncol Biol Phys. 2008;72(3):747-55.
4. Krishna Y, Coupland SE. Lacrimal sac tumors--a review. Asia Pac J Ophthalmol (Phila). 2017;6(2):173-8.

5. Sakaida H, Kobayashi M, Yuta A, Imanishi Y, Majima Y. Squamous cell carcinoma of the nasolacrimal duct. Eur Arch Otorhinolaryngol. 2009;266(3): 455-8.

6. Karcioglu ZA, Hadjistilianou D, Rozans M, DeFrancesco S. Orbital rhabdomyosarcoma. Cancer Control. 2004;11(5):328-33.

7. Holliday EB, Esmaeli B, Pinckard J, Garden AS, Rosenthal DI, Morrison WH, Kies MS, Gunn GB, Fuller CD, Phan J, et al. A multidisciplinary orbit-sparing treatment approach that includes proton therapy for epithelial tumors of the orbit and ocular adnexa. Int J Radiat Oncol Biol Phys. 2016;95(1):344-52.

8. Khan FM: The physics of radiation therapy, fourth edn: Lippincott Williams \& Wilkins; 2009

9. van de Water TA, Bijl HP, Schilstra C, Pijls-Johannesma M, Langendijk JA. The potential benefit of radiotherapy with protons in head and neck cancer with respect to normal tissue sparing: a systematic review of literature. Oncologist. 2011;16(3):366-77.

10. Frank SJ, Cox JD, Gillin M, Rosenthal DI, Garden AS, Ang KK, Mohan R, Palmer MB, Amin M, Zhu XR. Intensity modulated proton therapy for head-and-neck cancer: the first clinical experience. Int J Radiat Oncol Biol Phys. 2012;84:S475-6.

11. Frank SJ, Cox JD, Gillin M, Mohan R, Garden AS, Rosenthal DI, Gunn GB, Weber RS, Kies MS, Lewin JS, et al. Multifield optimization intensity modulated proton therapy for head and neck tumors: a translation to practice. Int J Radiat Oncol Biol Phys. 2014;89(4):846-53.

12. Tsujii H, Kamada T, Baba M, Tsuji H, Kato H, Kato S, Yamada S, Yasuda S, Yanagi T, Kato H, et al. Clinical advantages of carbon-ion radiotherapy. New J Phys. 2008;10:075009.

13. Kanai T, Endo M, Minohara S, Miyahara N, Koyama-ito $H$, Tomura $H$, Matsufuji N, Futami Y, Fukumura A, Hiraoka T, et al. Biophysical characteristics of HIMAC clinical irradiation system for heavy-ion radiation therapy. Int J Radiat Oncol Biol Phys. 1999;44(1):201-10.

14. Elsasser T, Kramer M, Scholz M. Accuracy of the local effect model for the prediction of biologic effects of carbon ion beams in vitro and in vivo. Int J Radiat Oncol Biol Phys. 2008;71(3):866-72.

15. Jones B. A simpler energy transfer efficiency model to predict relative biological effect for protons and heavier ions. Front Oncol. 2015;5:184.

16. Lu JD, Ye M, Guo Q, Fu JF, Moyers XM, Zhang ST, Mao NY, Kong YS, Hsi X, Shahnazi XY, et al. The preliminary report of a registration clinical trial of proton and heavy ion irradiation. Zhonghua Zhong Liu Za Zhi. 2018;40(1):52-6.

17. Emami B, Lyman J, Brown A, Coia L, Goitein M, Munzenrider JE, Shank B, Solin LJ, Wesson M. Tolerance of normal tissue to therapeutic irradiation. Int J Radiat Oncol Biol Phys. 1991;21(1):109-22.

18. Koto M. Skull base and upper cervical spine tumors. In: Tsujii H, Kamada T, Shirai T, et al., editors. In Carbon-Ion Radiotherapy Principles, Practices, and Treatment Planning. Heidelberg: Springer; 2014. p. 155-61.

19. Nieder C, Milas L, Ang KK. Tissue tolerance to reirradiation. Semin Radiat Oncol. 2000;10(3):200-9.

20. Aryasit O, Preechawai P, Hirunpat C, Horatanaruang O, Singha P. Factors related to survival outcomes following orbital exenteration: a retrospective, comparative, case series. BMC Ophthalmol. 2018;18(1):186.

21. Skinner HD, Garden AS, Rosenthal DI, Ang KK, Morrison WH, Esmaeli B, Pinnix CC, Frank SJ. Outcomes of malignant tumors of the lacrimal apparatus: the University of Texas MD Anderson Cancer Center experience. Cancer. 2011;117(12):2801-10.

22. Woo Kl, Sagiv O, Han J, Frank SJ, Kim YD, Esmaeli B. Eye-preserving surgery followed by adjuvant radiotherapy for lacrimal gland carcinoma: outcomes in 37 patients. Ophthalmic Plast Reconstr Surg. 2018;34(6):570-4.

23. Esmaeli B, Ahmadi MA, Youssef A, Diba R, Amato M, Myers JN, Kies M, ElNaggar A. Outcomes in patients with adenoid cystic carcinoma of the lacrimal gland. Ophthalmic Plast Reconstr Surg. 2004;20(1):22-6.

24. Tao R, Ma D, Takiar V, Frank SJ, Fuller CD, Gunn GB, Beadle BM, Morrison WH, Rosenthal DI, Edson MA, et al. Orbital carcinomas treated with adjuvant intensity-modulated radiation therapy. Head Neck. 2016; 38(Suppl 1):E580-7.

25. Esmaeli B, Yin VT, Hanna EY, Kies MS, William WN Jr, Bell D, Frank SJ. Eyesparing multidisciplinary approach for the management of lacrimal gland carcinoma. Head Neck. 2016;38(8):1258-62.

26. Ahmad SM, Esmaeli B, Williams M, Nguyen J, Fay A, Woog J, Selvadurai D, Rootman J, Weis E, Selva D, et al. American joint committee on Cancer classification predicts outcome of patients with lacrimal gland adenoid cystic carcinoma. Ophthalmology. 2009;116(6):1210-5. 
27. Woo Kl, Yeom A, Esmaeli B. Management of Lacrimal Gland Carcinoma: lessons from the literature in the past 40 years. Ophthalmic Plast Reconstr Surg. 2016;32(1):1-10.

28. Yang J, Gao J, Wu X, Hu J, Hu W, Kong L, Lu JJ. Salvage carbon ion radiation therapy for locally recurrent or radiation-induced second primary sarcoma of the head and neck. J Cancer. 2018;9(12):2215-23.

29. Jeganathan VS, Wirth A, MacManus MP. Ocular risks from orbital and periorbital radiation therapy: a critical review. Int J Radiat Oncol Biol Phys. 2011;79(3):650-9.

30. Petsuksiri J, Frank SJ, Garden AS, Ang KK, Morrison WH, Chao KS, Rosenthal DI, Schwartz DL, Ahamad A, Esmaeli B. Outcomes after radiotherapy for squamous cell carcinoma of the eyelid. Cancer. 2008;112(1):111-8.

31. Gordon KB, Char DH, Sagerman RH. Late effects of radiation on the eye and ocular adnexa. Int J Radiat Oncol Biol Phys. 1995;31(5):1123-39.

32. Batth SS, Sreeraman R, Dienes E, Beckett LA, Daly ME, Cui J, Mathai M, Purdy JA, Chen AM. Clinical-dosimetric relationship between lacrimal gland dose and ocular toxicity after intensity-modulated radiotherapy for sinonasal tumours. Br J Radiol. 2013;86(1032):20130459.

\section{Publisher's Note}

Springer Nature remains neutral with regard to jurisdictional claims in published maps and institutional affiliations.

Ready to submit your research? Choose BMC and benefit from:

- fast, convenient online submission

- thorough peer review by experienced researchers in your field

- rapid publication on acceptance

- support for research data, including large and complex data types

- gold Open Access which fosters wider collaboration and increased citations

- maximum visibility for your research: over $100 \mathrm{M}$ website views per year

At BMC, research is always in progress.

Learn more biomedcentral.com/submissions 